Research Article

\title{
Rutting Prediction Model of Asphalt Mixture Based on the Triaxial Repeated Load Test
}

\author{
Jie Ji $\mathbb{D}^{1,2,3}$ Meng Chen, ${ }^{1}$ Zhi Suo, ${ }^{1,2,3}$ Jianming Wei, ${ }^{4}$ Jiani Wang, ${ }^{1,2,3}$ and Lei Chen ${ }^{5}$ \\ ${ }^{1}$ School of Civil Engineering and Transportation, Beijing University of Civil Engineering and Architecture, Beijing 100044, China \\ ${ }^{2}$ Beijing Advanced Innovation Center for Future Urban Design, Beijing 100044, China \\ ${ }^{3}$ Beijing Collaborative Innovation Center for Energy Conservation \& Emission Reduction and Sustainable \\ Urban-Rural Development, Beijing 100044, China \\ ${ }^{4}$ National Institute of Clean-and-Low-Carbon Energy (NICE), Beijing 102211, China \\ ${ }^{5}$ Guangxi Transportation Research \& Consulting Co., Ltd., Guangxi, Nanning 530007, China
}

Correspondence should be addressed to Jie Ji; jijie@bucea.edu.cn

Received 30 January 2020; Revised 8 July 2020; Accepted 11 June 2021; Published 25 June 2021

Academic Editor: Jin Luo

Copyright (c) 2021 Jie Ji et al. This is an open access article distributed under the Creative Commons Attribution License, which permits unrestricted use, distribution, and reproduction in any medium, provided the original work is properly cited.

\begin{abstract}
This study establishes a more reasonable and effective rutting prediction model called the quadratic modified Burgers rheological model by considering dynamic loads. Use ABAQUS to simulate the rutting depths through the existing Burgers model and the quadratic modified model and compare with the measured values of the multitemperature and load rutting tests and triaxial repeated load tests. The real tests were conducted on four asphalt mixtures, including SK-90 asphalt mixture, styrene-butadienestyrene (SBS) modified asphalt mixture, direct coal liquefaction residue (DCLR) modified asphalt mixture, and compound DCLR modified asphalt mixture. The results showed that the range of error ratio and residual sum of squares between simulated and measured rutting depth based on the two different models are 5-35\%/5.0-8.74\% and 3-15\%/0.9-3.1\%, respectively, which show that the quadratic modified Burgers rheological model has a more accurate prediction.
\end{abstract}

\section{Introduction}

Establishing the rutting prediction model of asphalt mixture is the mainstream scheme to study the rutting resistance of asphalt pavement. The prediction of the model requires a feasible test method which can accurately reflect the characteristics of asphalt mixture to calibrate the parameters of the model [1-3]. Current tests can be roughly divided into two categories. One is the empirical test, such as the rutting test in lab and asphalt pavement analyzer test. At present, the rutting test in lab is one of the main methods to assess the rutting resistance of asphalt mixture in China. However, this kind of test cannot directly reflect the mechanical properties of materials, so the model established by it has certain limitations. Another kind of test is based on mechanical principles, such as the uniaxial creep test and triaxial repeated load test [4-6]. Because there is a linear relationship between stress and strain of specimens in this kind of test, mechanical parameters reflecting material properties can be calculated and a complete rutting prediction model can be established. The uniaxial test equipment is simple and easy to implement. However, due to the lack of lateral restraint, the stress state of specimen is different from that of actual road surface [7]. Therefore, multiaxial repeated tests, for example, the triaxial repeated load test, were considered as a more suitable choice.

It is proven that the triaxial repeated load test with adjustable lateral confining pressure and dynamic load can better simulate the actual stress state of asphalt pavement $[8,9]$. The reports from NCHRP (the National Cooperative Highway Research Program) and SHRP (Strategic Highway Research Program) recommend the dynamic modulus test, triaxial static creep test, and triaxial repeated load test to assess the rutting resistance of asphalt mixture $[10,11]$. 
G. Cerni put forward a simplified method based on the triaxial repeated load test, which can accurately predict the material characteristics by adjusting the combination of stress and applied stress direction [12]. Park verified the effect of temperature on asphalt mixture by the triaxial repeated load test and predicted the relationship between temperature and rutting by the temperature conversion factor [13]. Zhang et al. studied the triaxial repeated load test and put forward the complete test parameters and method flow $[14,15]$. Thus, the triaxial repeated load test is widely considered to be the most accurate and feasible test method to reflect the characteristics of asphalt mixture.

At present, the rutting prediction models of asphalt pavement can be roughly divided into two categories: empirical model and rheological model [16]. Archilla et al. put forward the empirical rutting prediction model based on AASHTO test pavement data. It has strong pertinence, but the cost of such models is high and the overall effect of pavement structure is not considered. Therefore, its scope of application is narrow. The rheological model is currently widely used [17]. Blab et al. used the Maxwell model to calculate the stress-strain response of asphalt pavement under load. The results show that the rheological model can effectively predict the asphalt pavement depth [18]. Loay et al. established a two-dimensional finite element model by the Pellinen and Witczak models and analyzed that the asphalt pavement rutting has high sensitivity to high temperature and heavy load [19]. Zhang obtained the dynamic modulus prediction model of asphalt mixture according to the Witczak model and verified that the model is feasible to predict the dynamic modulus of asphalt mixtures when the temperature is lower than $45^{\circ} \mathrm{C}$ [20]. Mackiewicz et al. calibrated the rheological parameters based on the Burgers model by static and dynamic creep tests and verified that this method can be used for predicting the permanent deformation of asphalt pavement [21]. Xu et al. obtained the deformation characteristics of asphalt mixture according to the uniaxial creep test and proposed a modified Burgers model, which can better represent the "consolidation effect" of asphalt mixture [22]. Huang et al. modeled and analyzed the uniaxial creep test of asphalt mixture by the modified Burgers model. The results show that the model can better characterize the different stages of creep of asphalt mixture [23]. Thus, it is generally believed that the modified Burgers model can accurately reflect the deformation law of asphalt mixture.

On the other hand, in order to solve the energy problem, a large amount of direct coal liquefaction residue (DCLR) is produced every year in China, which can be used as a good modifier of asphalt. At present, there is no efficient method of DCLR utilization, and it is simply being stacked and burned [24]. This will not only cause serious damage to the environment but also be a waste of resources. The previous research of our group shows that DCLR can be developed as a modifier and improve the high temperature performance and water stability of asphalt mixture $[25,26]$. Unfortunately, there is no research on the rutting model of DCLR.

\section{Objectives and Procedures}

The motivation of this study is to establish the rutting prediction model of asphalt mixture based on the triaxial repeated load test.

First, the triaxial repeated load test and multitemperature and load rutting test were conducted on asphalt mixture. The rutting depth of asphalt mixture was simulated based on the existing modified Burgers model and compared with the measured value in the multitemperature and load rutting test.

Second, the quadratic modified Burgers model and parameters were remodified based on the triaxial repeated load test, and the rutting prediction model was reconstructed. Then, the rutting depth based on the quadratic modified Burgers model was simulated and also compared with the measured value in the multitemperature and load rutting test.

Finally, the error ratios and residual sum of squares of simulated and measured rutting depths were calculated and compared to verify the rationality and effectiveness of the abovementioned two rutting prediction models, respectively.

\section{Test Materials and Methods}

3.1. Test Material. The raw materials included DCLR, four kinds of asphalt binders, and three kinds of aggregates. Additionally, the DCLR, provided by China SHENHUA Co., Ltd., is a solid powder at room temperature and its melting point is $170^{\circ} \mathrm{C}$. The four kinds of asphalt binders were SK-90 asphalt, SBS modified asphalt, DCLR, and composite DCLR modified asphalt. Limestone was used for coarse aggregate and fine aggregate, and limestone powder was used for mineral powder. The properties of raw materials were referred to the previous research studies of our group $[25,26]$.

The four kinds of asphalt mixtures included SK-90 asphalt mixture, SBS modified asphalt mixture, DCLR modified asphalt mixture, and composite DCLR modified asphalt mixture. They had the same gradation (AC-20) and optimum asphalt content (4.3\%). Their performances were also referred to the previous research studies of our group $[25,26]$.

3.2. Multitemperature and Load Rutting Test. According to T0719-2011 in JTG E20-2011 specified in China [27], the size of each sample is width $300 \mathrm{~mm}^{*}$ length $300 \mathrm{~mm}{ }^{*}$ height $50 \mathrm{~mm}$, the test temperature is $60^{\circ} \mathrm{C}$, and the test wheel pressure is $0.7 \mathrm{MPa}$. However, in most areas of China, such as Turpan, Chongqing, Wuhan, and so on, the maximum temperature of asphalt pavement can reach about $70^{\circ} \mathrm{C}$, and the wheel load of heavy-duty vehicles and overloaded vehicles can reach 1.0 MPa [28]. In order to consider the influence of the most unfavorable temperature and heavy load conditions on the high temperature characteristics of asphalt pavement, the test conditions were extended according to the specifications as follows:

(i) The test temperature is $55^{\circ} \mathrm{C}, 60^{\circ} \mathrm{C}, 65^{\circ} \mathrm{C}$, and $70^{\circ} \mathrm{C}$

(ii) The test wheel pressure is $0.7 \mathrm{MPa}, 0.8 \mathrm{MPa}, 0.9 \mathrm{MPa}$, and $1.0 \mathrm{MPa}$ 
The test will stop automatically after 60 mins or the accumulated deformation reaches $25 \mathrm{~mm}$. Each test condition is repeated three times, and the average value is taken if the coefficient of variation is less than $20 \%$. The rutting tester independently developed by the research group is used in the test, as shown in Figure 1.

3.3. Triaxial Repeated Load Test. According to the improvement of T0718-2011 in JTG E20-2011 specified in China [27], the asphalt mixture was formed by rotary compaction, and the cylindrical specimen with diameter of $100 \mathrm{~mm}$ and high $160 \mathrm{~mm}$ was obtained through core drilling. The cutting machine was used to cut the test piece for ensuring the flatness of both ends of the piece. The height of the test piece is $150 \pm 2 \mathrm{~mm}$, and the void ratio is $4.3 \pm 0.5 \%$, as shown in Figure 2. The IPC UTM-25 pneumatic servo test instrument is selected for the test, with a total of 12 test conditions, as shown in Figure 3. The test will stop automatically after 10000 cycles of loading or more than $5 \%$ permanent deformation of the piece. Each test condition is repeated three times, and the average value is taken if the coefficient of variation is less than $20 \%$. The test conditions are as follows:

(i) The preloading is $90 \mathrm{~s}$ vertical load, and the load level is $0.01 \mathrm{MPa}$.

(ii) The test temperature is $50^{\circ} \mathrm{C}, 60^{\circ} \mathrm{C}$, and $70^{\circ} \mathrm{C}$

(iii) The test load level is $0.7 \mathrm{MPa}, 0.8 \mathrm{MPa}, 0.9 \mathrm{MPa}$, and 1.0 $\mathrm{MPa}$; the lateral pressure is $0.138 \mathrm{MPa}$;

(iv) The loading mode is half sine wave intermittent load (0.1 s loading, $0.9 \mathrm{~s}$ unloading)

\section{Test Results and Discussion}

4.1. Existing Modified Burgers Model. A large number of studies show that the deformation process of asphalt mixture in the triaxial repeated load test is divided into three stages, which are the first stabilization stage, the second migration stage, and the third failure stage [29-31]. Since there is no obvious law for the third failure stage, this study only analyzed the data obtained from the stabilization and migration period. The relationships between the permanent deformations and the load numbers under different temperatures and loads are shown in Figure 4. It can be seen that under the same load condition, temperature is positively correlated with the permanent deformation of asphalt mixture. Under the same temperature condition, the load is positively correlated with the permanent deformation degree of asphalt mixture. Under the same load and temperature, the order of permanent deformation relationship of the four asphalt mixtures is as follows: SK-90 asphalt mixture $>$ DCLR modified asphalt mixture $>$ SBS modified asphalt mixture $>$ composite DCLR modified asphalt mixture.

Currently, the existing rheological model which can accurately describe the rutting resistance of asphalt mixture

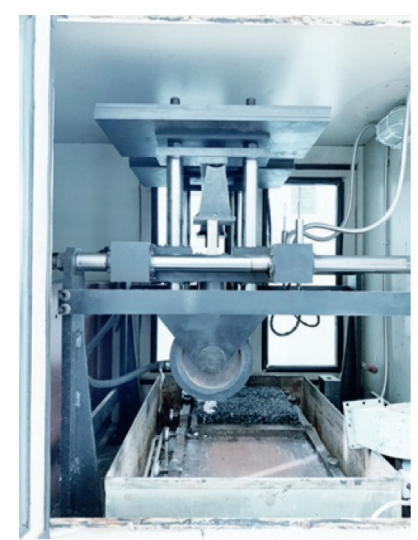

Figure 1: Rutting tester.

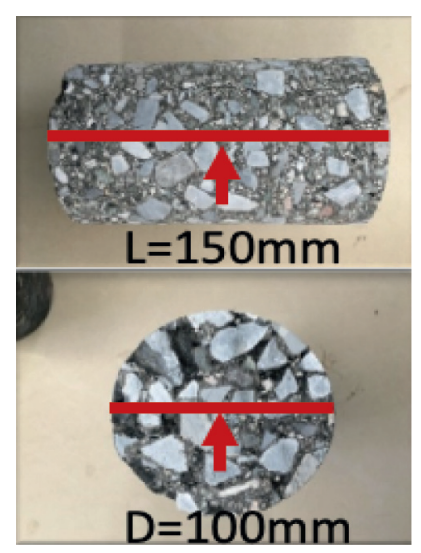

Figure 2: Triaxial test specimen.

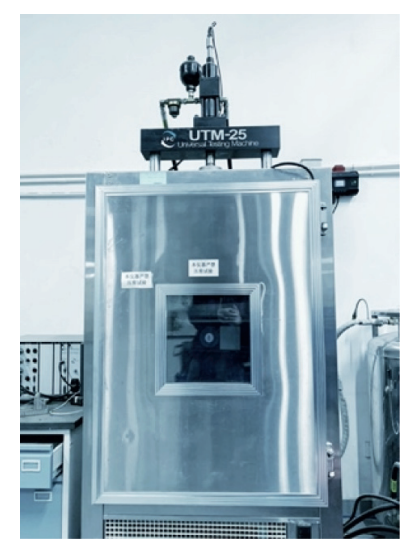

Figure 3: IPC UTM-25 triaxial tester.

is the Burgers model which is modified by external clay pot $[32,33]$. The load process strain of modified Burgers model is given as

$$
\varepsilon=\sigma\left[\frac{1}{E_{1}}+\frac{1-e^{-B t}}{\mathrm{AB}}+\frac{\left(1-e^{-\left(E_{2} * t / \eta_{2}\right)}\right)}{E_{2}}\right]
$$

where $\sigma$ is the applied load; $\varepsilon$ is the strain; E1 and E2 are the elastic modulus of the internal and external springs, 

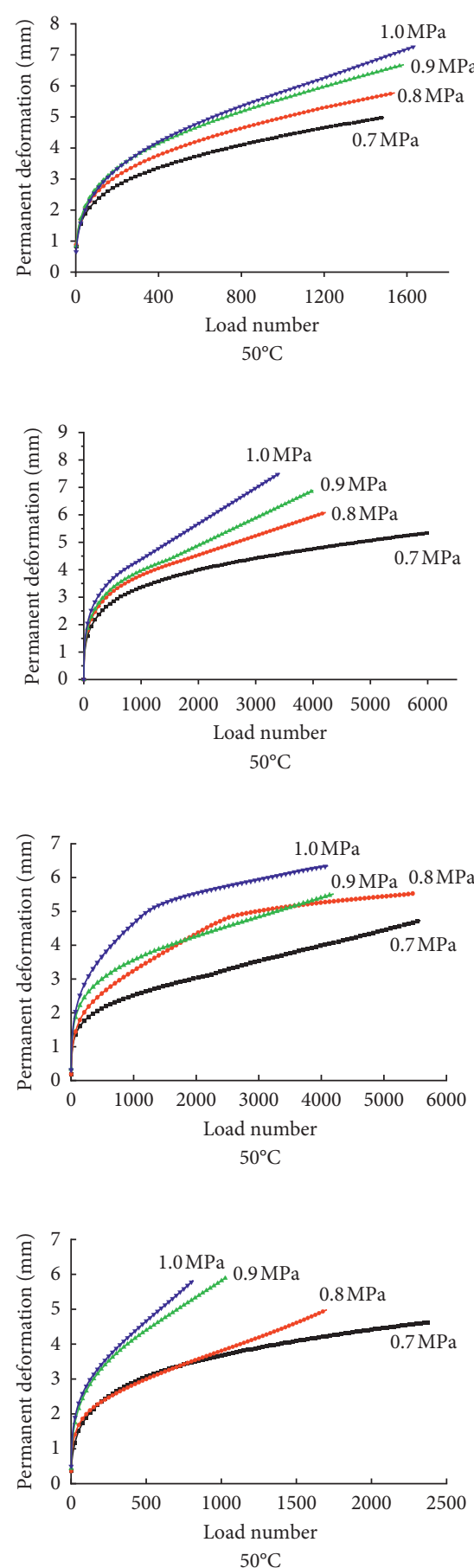

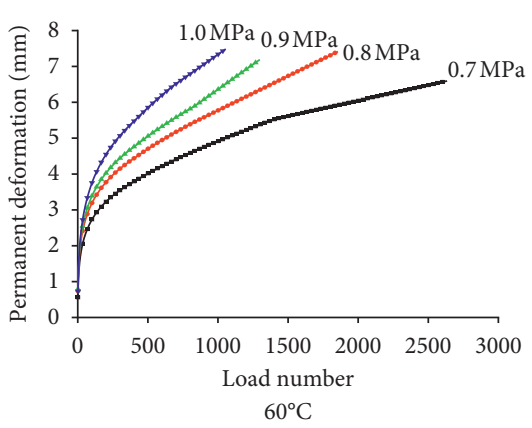

(a)

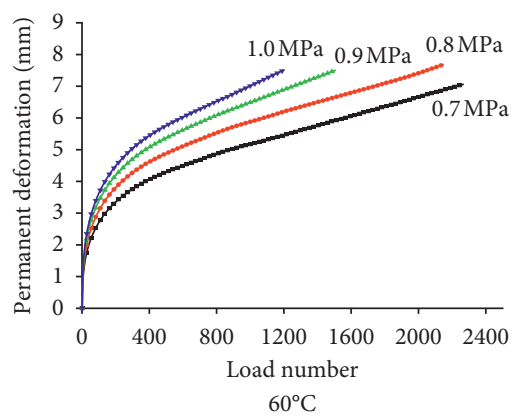

(b)

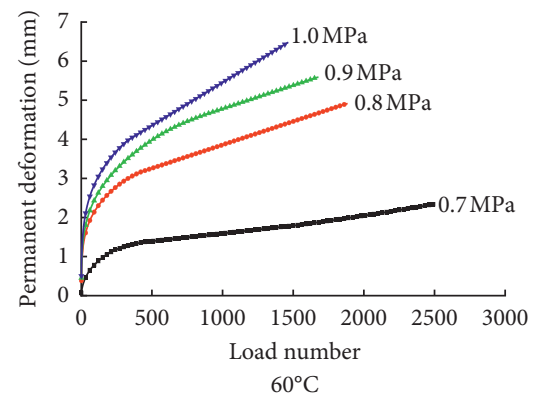

(c)

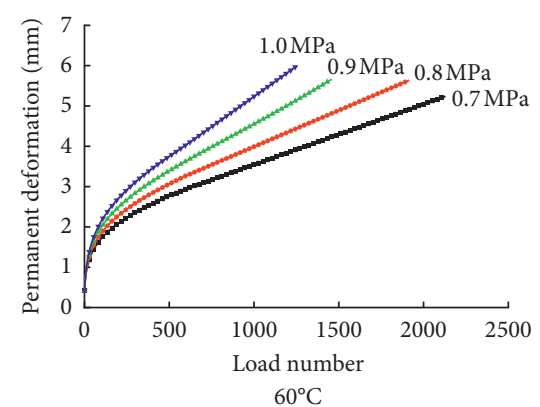

(d)
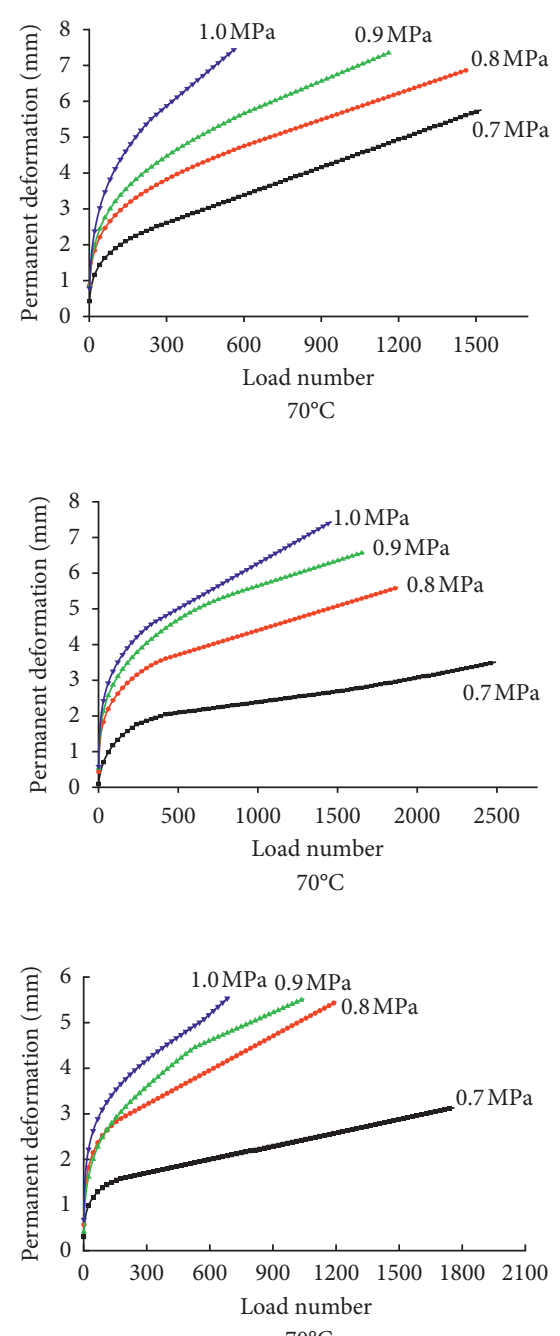

$70^{\circ} \mathrm{C}$

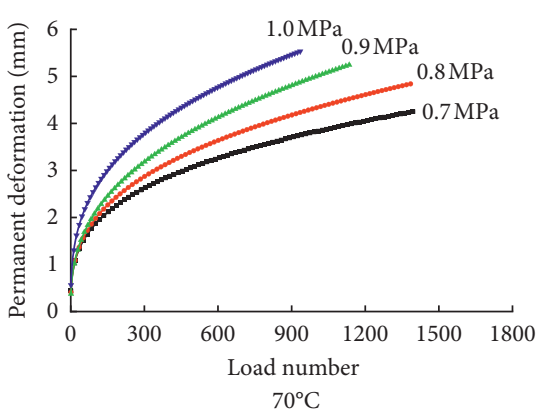

Figure 4: Permanent deformations over load numbers under different temperatures and loads. (a) SK-90 asphalt mixture 506070. (b) SBS modified asphalt mixture. (c) DCLR modified asphalt mixture. (d) Composite DCLR modified asphalt mixture.

respectively; $\eta 1$ and $\eta 2$ are the viscosity coefficients of the internal and external viscous pots, respectively; $t$ is the time; and $A$ and $B$ are the parameters of the modified Burgers model.

Formula (2) shows the unloading process strain:

$$
\varepsilon=\sigma\left[\frac{1-e^{-B t_{0}}}{\mathrm{AB}}+\left(1-e^{-E_{2}{ }^{*}\left(t / \eta_{2}\right)}\right) e^{-E_{2}{ }^{*}\left(t-\left(t_{0} / \eta_{2}\right)\right)}\right],
$$

where $t_{0}$ is the loading time, and other parameters are the same as formula (1). 
The existing modified Burgers rheological model and triaxial repeated load test data are combined to build the rutting prediction model. The rutting depth of four kinds of asphalt mixtures under the same conditions as 16 kinds of multitemperature and load rutting tests is calculated, that is, rutting depth under different temperatures $\left(55^{\circ} \mathrm{C}, 60^{\circ} \mathrm{C}, 65^{\circ} \mathrm{C}\right.$, and $70^{\circ} \mathrm{C}$ ) and loads (0.7 MPa, 0.8 MPa, 0.9 MPa, and 1.0 MPa).

Table 1 compares the predicted rutting depth based on the modified Burgers prediction model and the measured rutting depth using the multitemperature and load rutting test.

It can be seen from Table 1 that the error ratio ranges from $5 \%$ to $35 \%$, and the residual sum of squares changes from $5.0 \%$ to $8.74 \%$. It is generally believed that the smaller the error rate and the residual sum of squares, the closer the two sets of data are. Numerous studies show that, if the residual sum of squares is less than $5 \%$, it is considered that the correlation between the two sets of data is relatively high. Obviously, the existing modified Burgers model cannot accurately simulate the deformation characteristics of asphalt mixture $[34,35]$. This is mainly because the viscoelastic parameters of the existing modified Burgers model are calibrated by the uniaxial static creep test, so it is more suitable for rutting prediction under static load but not for dynamic load. Because the dynamic load can simulate the actual road stress state more accurately, therefore, it is necessary to remodify the model to improve the accuracy.

4.2. The Quadratic Modified Burgers Model. Since the viscoelastic parameters of the existing Burgers model are calibrated by the uniaxial static creep test, it is only suitable for the prediction of rutting under static load, but not suitable for simulation under intermittent load. Therefore, the remodified existing Burgers model based on the triaxial repeated load test aimed to consider dynamic loads. The main ideas of remodification include the following. First, the independent variable time of the uniaxial static creep test is converted to the number of times of the triaxial repeated load test. Second, the static load is converted into semisinusoidal intermittent load. Finally, the loading strain is converted into loading and unloading strain, and the quadratic modified Burgers model considering dynamic load is obtained.

The steps of remodification are as follows:

(1) Strain conversion: since the stress-strain at time $t$ is equal to the sum of all the stress-strain at time from 0 to $t$ and the unloading stress $\sigma$ at time $t$ is equal to applying a reverse $-\sigma$, the sum of the loading and unloading strains is converted into

$$
\varepsilon(\mathrm{t})=\sigma_{0}\left[\frac{\left(1-e^{-B t_{0}}\right) e^{-B\left(t-t_{0}\right)}}{\mathrm{AB}}+e^{-E_{2} *\left(\left(t-t_{0}\right) / \eta_{2}\right)} \frac{\left(1-e^{-E_{2} *\left(t_{0} / \eta_{2}\right)}\right)}{E_{2}}\right]
$$

In equation ( 3 ), $\sigma_{0}$ is the equivalent static load axial compressive stress level, and other parameters are the same as in formula (1).

(2) Load form conversion: the load form of the triaxial load test is half sine wave intermittent load as

$$
\sigma_{t}=\left\{\begin{array}{ll}
\sigma \sin \frac{\pi}{t_{0}} t, & 0 \leq t \leq t_{0} \\
0, & t_{0} \leq t \leq T
\end{array} t_{0}=0.1 s, T=1 s\right.
$$

In equation (4), $t$ is the load period, $\sigma_{t}$ is the maximum load at time $t$, and other parameters are the same as in formula (1).

According to the principle of stress equivalent impulse, the stress load of half sine wave is transformed into equivalent load as

$$
\sigma_{0}=\frac{2}{\pi} \sigma
$$

(3) Independent variable conversion: the independent variable in formula (5) is converted from time $T$ to number of actions $N$ by the method of derivative of strain rate, and the strain produced in the $i^{\text {th }}$ time is recorded as $\varepsilon_{N i}$; then, the permanent strain rate of the $N^{\text {th }}$ time is

$$
\begin{aligned}
\mathcal{E}_{N}-\varepsilon_{N-1}= & \frac{\sigma_{0} 1-e^{B t_{0}} e^{-B[N-\mathrm{i}] T+t_{d}}}{A B} \\
& +\frac{1-e^{-t t_{0}}}{E_{2}}\left(e^{-\tau\left[(N-1) T+t_{d}\right]}\right) .
\end{aligned}
$$

In equation (6), $\tau=E_{2} / \eta_{2}$ is the parameter of the parallel spring and the glue pot of the modified Burgers model; the other parameters are the same as in formula (1).

By integrating formula (6), the function relationship between permanent deformation and $N$ is obtained, that is, the quadratic modified Burgers model considering dynamic load as the following formula.

$$
\varepsilon=\frac{\sigma_{0}\left(e^{B t_{0}}-1\right)}{A B^{2} T}\left(1-e^{-B T N}\right)+\frac{\sigma_{0}\left(e^{\tau t_{0}}-1\right)}{E_{2} \tau T} 1-e^{-\tau T N} .
$$

4.3. Rutting Prediction Based on the Quadratic Modified Burgers Model. Use Origin 9.0 to fit the triaxial repeated load test data with the quadratic modified Burgers model by 
TABLE 1: Error ratios and residual sum of squares of simulated and measured rutting depths.

\begin{tabular}{lcc}
\hline Type of mixture & Error ratio (\%) & Residual sum of squares (\%) \\
\hline SK-90 asphalt mixture & $8-27$ & 5.00 \\
SBS modified asphalt mixture & $5-26$ & 8.74 \\
DCLR modified asphalt mixture & $8-35$ & 7.36 \\
Composite DCLR modified asphalt mixture & $8-34$ & 8.27 \\
\hline
\end{tabular}

Note. The error ratio is the ratio of the difference between the predicted and experimental values of rutting depth, and the residual sum of squares is the discretization degree of the fitting curve between the predicted and experimental values of rutting depth.

TABLE 2: Rheological parameters of asphalt mixtures.

\begin{tabular}{|c|c|c|c|c|c|c|c|c|c|c|c|c|c|c|c|}
\hline \multirow{2}{*}{ Temperature $\left({ }^{\circ} \mathrm{C}\right)$} & \multirow{2}{*}{ Load $(\mathrm{MPa})$} & \multicolumn{7}{|c|}{ SK-90 asphalt mixture } & \multicolumn{7}{|c|}{ SBS modified asphalt mixture } \\
\hline & & $A$ & $B$ & $\varepsilon_{2}$ & $\eta_{1}$ & $\varepsilon_{1}$ & $R^{2}$ & $P$ & $A$ & $B$ & $\varepsilon_{2}$ & $\eta_{1}$ & $\varepsilon_{1}$ & $R^{2}$ & $P$ \\
\hline 50 & 0.7 & 0.71 & 0.89 & 2.47 & 83.20 & 4.53 & 0.99 & 0.00 & 1.08 & 1.34 & 3.70 & 124.80 & 6.80 & 0.92 & 0.01 \\
\hline 60 & 0.7 & 0.66 & 0.82 & 2.39 & 82.53 & 4.11 & 0.98 & 0.01 & 1.01 & 1.27 & 3.59 & 123.79 & 6.17 & 0.93 & 0.01 \\
\hline 70 & 0.7 & 0.57 & 0.73 & 2.19 & 80.03 & 2.96 & 0.91 & 0.01 & 0.84 & 1.10 & 3.28 & 120.05 & 4.46 & 0.94 & 0.00 \\
\hline 50 & 0.8 & 0.67 & 0.85 & 2.40 & 79.45 & 4.17 & 0.90 & 0.01 & 1.02 & 1.28 & 3.61 & 119.18 & 6.26 & 0.93 & 0.01 \\
\hline 60 & 0.8 & 0.62 & 0.80 & 2.32 & 78.01 & 3.63 & 0.91 & 0.01 & 0.94 & 1.20 & 3.46 & 117.03 & 5.45 & 0.94 & 0.01 \\
\hline 70 & 0.8 & 0.51 & 0.69 & 2.10 & 74.74 & 2.49 & 0.90 & 0.02 & 0.76 & 1.03 & 3.15 & 112.12 & 3.74 & 0.83 & 0.02 \\
\hline 50 & 0.9 & 0.65 & 0.83 & 2.35 & 73.69 & 3.87 & 0.99 & 0.01 & 0.99 & 1.24 & 3.52 & 110.54 & 5.81 & 0.92 & 0.01 \\
\hline 60 & 0.9 & 0.46 & 0.64 & 2.02 & 69.66 & 2.01 & 0.91 & 0.01 & 0.71 & 0.96 & 3.02 & 104.49 & 3.02 & 0.95 & 0.01 \\
\hline 70 & 0.9 & 0.30 & 0.55 & 1.86 & 64.29 & 1.17 & 0.90 & 0.01 & 0.57 & 0.83 & 2.81 & 96.43 & 1.76 & 0.99 & 0.00 \\
\hline 50 & 1.0 & 0.54 & 0.72 & 2.15 & 61.50 & 2.79 & 0.97 & 0.00 & 0.81 & 1.08 & 3.23 & 92.25 & 4.19 & 0.98 & 0.00 \\
\hline 60 & 1.0 & 0.61 & 0.89 & 3.02 & 92.91 & 1.56 & 0.93 & 0.01 & 0.53 & 0.79 & 2.71 & 82.69 & 1.40 & 0.88 & 0.01 \\
\hline 70 & 1.0 & 0.45 & 0.73 & 2.76 & 80.81 & 0.76 & 0.97 & 0.00 & 0.41 & 0.63 & 2.45 & 71.88 & 0.72 & 0.81 & 0.02 \\
\hline \multirow{2}{*}{ Temperature $\left({ }^{\circ} \mathrm{C}\right)$} & \multirow{2}{*}{ Load (MPa) } & \multicolumn{7}{|c|}{ DCLR modified asphalt mixture } & \multicolumn{7}{|c|}{ Composite DCLR modified asphalt mixture } \\
\hline & & $A$ & $B$ & $\varepsilon_{2}$ & $\eta_{1}$ & $\varepsilon_{1}$ & $R^{2}$ & $P$ & $A$ & $B$ & $\varepsilon_{2}$ & $\eta_{1}$ & $\varepsilon_{1}$ & $R^{2}$ & $P$ \\
\hline 50 & 0.7 & 0.83 & 1.32 & 3.67 & 123.42 & 6.73 & 0.96 & 0.00 & 1.19 & 1.50 & 4.11 & 138.8 & 7.55 & 0.88 & 0.01 \\
\hline 60 & 0.7 & 1.01 & 1.26 & 3.55 & 122.42 & 6.11 & 0.92 & 0.01 & 0.94 & 1.42 & 3.99 & 137.6 & 6.86 & 0.96 & 0.01 \\
\hline 70 & 0.7 & 1.07 & 1.09 & 3.25 & 118.72 & 4.41 & 0.97 & 0.01 & 1.13 & 1.23 & 3.65 & 133.4 & 4.96 & 0.99 & 0.00 \\
\hline 50 & 0.8 & 1.04 & 1.29 & 3.55 & 117.83 & 6.33 & 0.89 & 0.01 & 1.14 & 1.43 & 4.01 & 132.4 & 6.96 & 0.98 & 0.01 \\
\hline 60 & 0.8 & 0.93 & 1.19 & 3.43 & 115.73 & 5.39 & 0.89 & 0.01 & 1.05 & 1.34 & 3.85 & 130.1 & 6.06 & 0.99 & 0.00 \\
\hline 70 & 0.8 & 0.77 & 1.02 & 3.12 & 110.89 & 3.71 & 0.81 & 0.02 & 0.86 & 1.18 & 3.53 & 124.6 & 4.18 & 0.82 & 0.02 \\
\hline 50 & 0.9 & 0.97 & 1.23 & 3.49 & 109.32 & 5.75 & 0.87 & 0.01 & 0.78 & 1.38 & 3.92 & 122.8 & 6.46 & 0.87 & 0.01 \\
\hline 60 & 0.9 & 0.69 & 0.95 & 2.99 & 103.34 & 2.99 & 0.89 & 0.01 & 1.09 & 1.07 & 3.36 & 116.1 & 3.36 & 0.89 & 0.01 \\
\hline 70 & 0.9 & 0.57 & 0.83 & 2.77 & 95.36 & 1.74 & 0.94 & 0.01 & 0.64 & 0.93 & 3.11 & 107.2 & 1.96 & 0.98 & 0.01 \\
\hline 50 & 1.0 & 0.82 & 1.08 & 3.21 & 91.22 & 4.16 & 0.98 & 0.00 & 0.92 & 1.19 & 3.60 & 102.4 & 4.65 & 0.95 & 0.01 \\
\hline 60 & 1.0 & 0.53 & 0.79 & 2.71 & 82.69 & 1.39 & 0.88 & 0.01 & 0.61 & 0.89 & 3.12 & 92.91 & 1.56 & 0.93 & 0.02 \\
\hline 70 & 1.0 & 0.42 & 0.62 & 2.43 & 71.92 & 0.77 & 0.81 & 0.02 & 0.44 & 0.73 & 2.75 & 80.82 & 0.76 & 0.97 & 0.01 \\
\hline
\end{tabular}

the least square method and get rheological parameters $A, B$, $\varepsilon_{1}, \varepsilon_{2}, \eta_{1}$ by regression analysis. Among them, $A$ and $B$ are the parameters of the modified pots in the modified Burgers model; $\varepsilon_{1}$ and $\varepsilon_{2}$ are the strain variables; and $\eta_{1}$ is the viscosity coefficient of the clay pot. Table 2 provides the rheological parameters of four asphalt mixtures.

As given in Table 2, the value of determination coefficient $R^{2}$ is $0.81-0.99$, and the significance $P$ value is $0.00-0.02$, indicating that there is a significant linear correlation between the triaxial repeated load test data and the quadratic modified Burgers model. The quadratic modified Burgers model can simulate the relevance between the permanent deformation and the load numbers effectively, and the rheological parameters can also accurately characterize the deformation characteristics of asphalt mixture.

With ABAQUS software, the rheological parameters determined in Table 2 are used as input parameters to build the rutting prediction model of asphalt mixture. Because
ABAQUS software cannot directly input the rheological parameters of materials, the Prony series method is used to transform the calibrated rheological parameter $A, B, \varepsilon_{1}, \varepsilon_{2}$, and $\eta_{2}$ into $g_{1}, g_{2}, \tau 1$, and $\tau 2$ of shear modulus, so that they can be identified by ABAQUS software. The number of iterations in the transformation process is 2 times, as given in Table 3.

2D models of four kinds of asphalt mixtures are constructed, respectively, to calculate the strain of flat shell elements. The rutting depth of four kinds of asphalt mixtures under the same conditions as 16 kinds of multitemperature and load rutting tests is calculated. In order to reduce the influence of variables on the simulation results, the dimension of the finite element model is the same as that of the rutting plate in the multitemperature and load rutting test, the size is $300 \mathrm{~mm} * 5 \mathrm{~mm}$, and Figure 5 shows that the force situation of the simulated rutting prediction model. 
TABLe 3: Shear modulus of asphalt mixtures.

\begin{tabular}{lcccc}
\hline $\begin{array}{l}\text { Shear } \\
\text { modulus }\end{array}$ & $\begin{array}{c}\text { SK-90 asphalt } \\
\text { mixture }\end{array}$ & $\begin{array}{c}\text { SBS modified asphalt } \\
\text { mixture }\end{array}$ & $\begin{array}{c}\text { DCLR modified asphalt } \\
\text { mixture }\end{array}$ & $\begin{array}{c}\text { Composite DCLR modified asphalt } \\
\text { mixture }\end{array}$ \\
\hline$\tau 1$ & $0.31-0.35$ & $0.578-0.77$ & $0.64-0.69$ & $1.008-1.158$ \\
$\tau 2$ & $0.81-0.9$ & $0.62-0.68$ & $0.71-0.76$ & $0.44-0.68$ \\
$g_{1}$ & $24520-27890$ & $10997-14785$ & $11035-13478$ & $7680-8911$ \\
$g_{2}$ & $31-58$ & $75-102$ & $60-98$ & $157-195$ \\
\hline
\end{tabular}

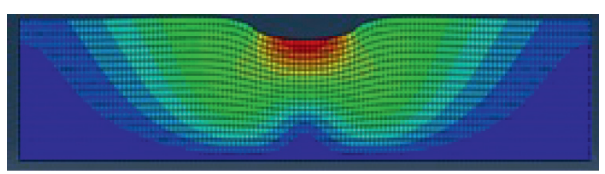

Figure 5: Finite element model schematic diagram.

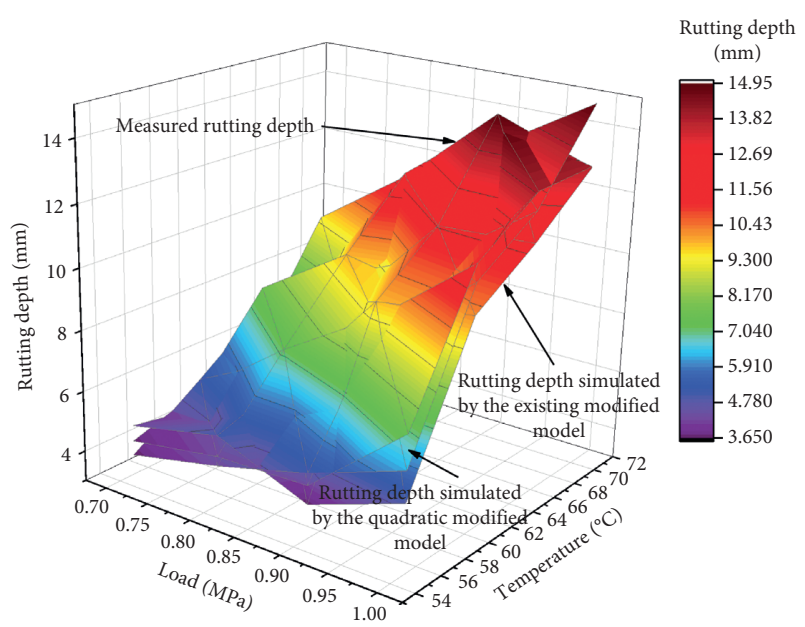

(a)

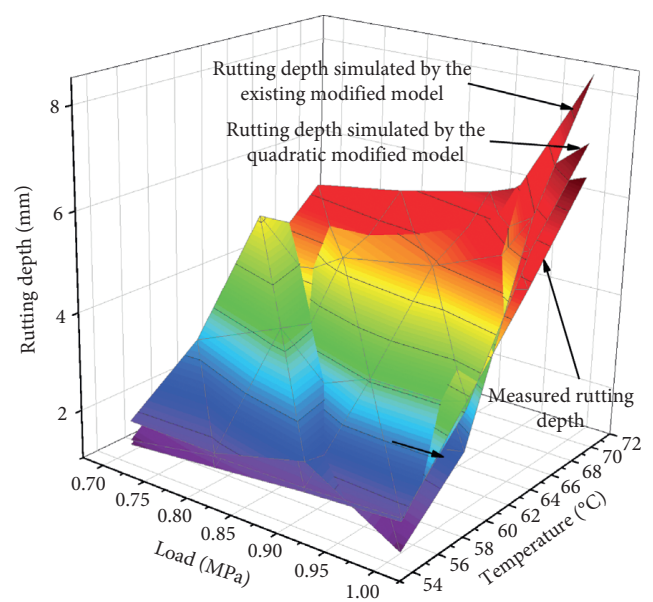

(c)

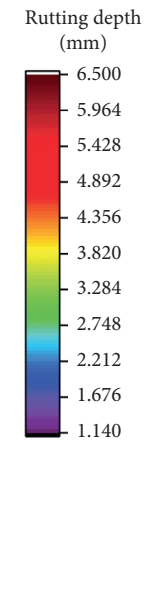

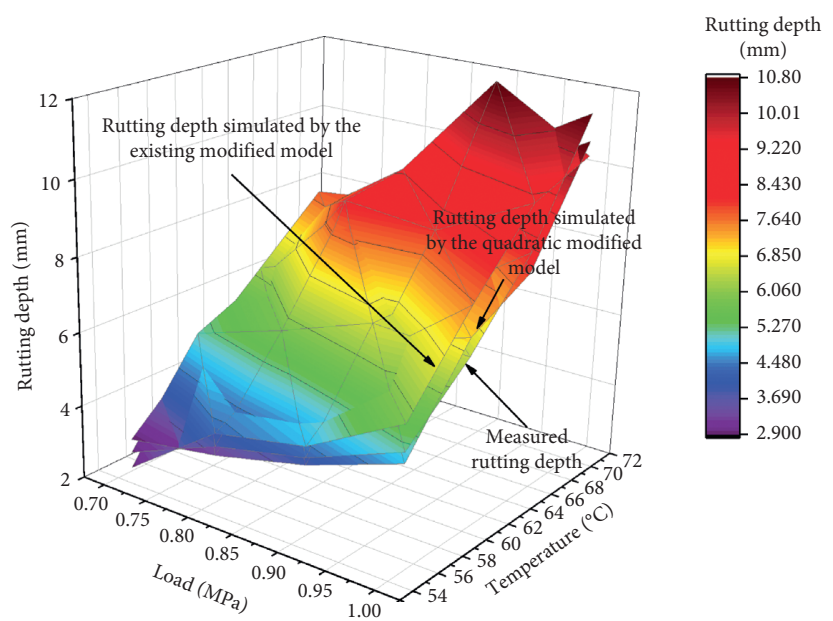

(b)

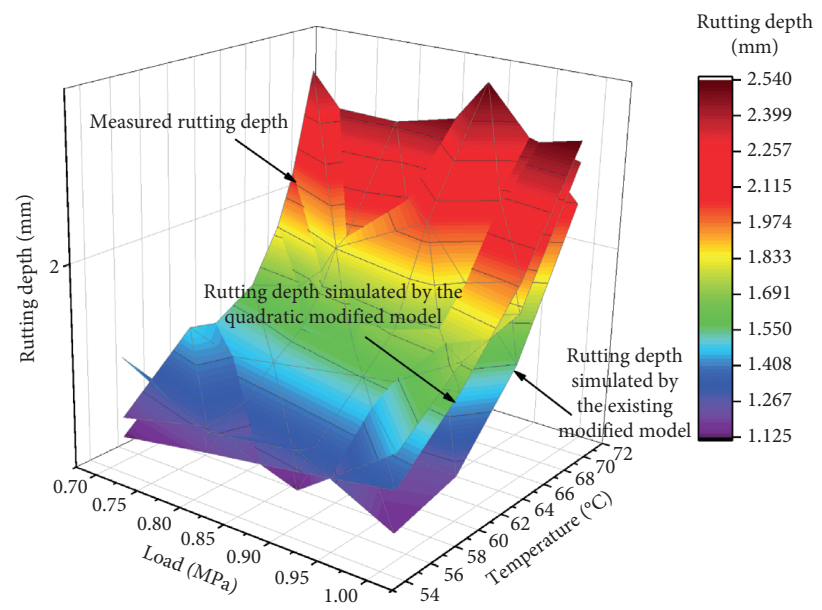

(d)

FIGURE 6: Comparisons on simulated and measured rutting depths. (a) SK-90 asphalt mixture. (b) SBS modified asphalt mixture. (c) DCLR modified asphalt mixture. (d) Composite DCLR modified asphalt mixture. 
TABLE 4: Error ratios and residual sum of squares of measured and simulated rutting depths.

\begin{tabular}{|c|c|c|c|c|}
\hline \multirow{2}{*}{ Type of mixture } & \multicolumn{2}{|c|}{ Quadratic modified burgers model } & \multicolumn{2}{|c|}{ Existing modified burgers model } \\
\hline & Error ratios (\%) & Residual sum of squares (\%) & Error ratios (\%) & Residual sum of squares (\%) \\
\hline SK-90 asphalt mixture & $5-12$ & 2.05 & $8-27$ & 5.00 \\
\hline SBS modified asphalt mixture & $4-11$ & 2.21 & $5-26$ & 8.74 \\
\hline DCLR modified asphalt mixture & $3-12$ & 3.10 & $8-35$ & 7.36 \\
\hline $\begin{array}{l}\text { Composite DCLR modified asphalt } \\
\text { mixture }\end{array}$ & $4-10$ & 0.94 & $8-34$ & 8.27 \\
\hline
\end{tabular}

4.4. Comparison on the Two Rutting Prediction Models. The rutting depths were calculated based on the existing modified Burgers model and quadratic modified Burgers model and compared with the measured rutting depths in the multitemperature and load rutting test, as shown in Figure 6.

Table 4 provides the error ratios and residual sums of squares between the estimated and measured rutting depths based on the two models.

From Figure 6 and Table 4, it can be concluded that the error ratio between the predicted rutting depth and the measured rutting depth in the indoor multitemperature and load rutting test is $3-12 \%$, and the residual sum of squares is 0.94-3.10\%. Compared with the estimated values based on the existing modified Burgers model, the error ratio and residual sum of squares of rutting depth are reduced by about $70 \%$ and $60 \%$, respectively. It shows the accuracy of the results is significantly improved, which can reflect the rutting resistance of asphalt mixture more accurately.

\section{Conclusions}

Through the above tests and analysis, some conclusions can be drawn:

(i) The error ratio and residual sum of squares of the rutting depth simulated by the existing modified Burgers model between the measured values in the multitemperature and load rutting test is high, which indicates the model is not suitable for predicating the rutting resistance of asphalt mixture

(ii) The quadratic modified Burgers model considering dynamic loads was built by the existing modified Burgers model through changes in independent variable, load form, and the transformation of loading and unloading strain. The least square method is used to fit the triaxial repeated load test data with the model, and the $R^{2}$ value is greater than 0.8 , which means the quadratic modified Burgers model has a good correlation with the triaxial repeated load test.

(iii) Compared with the rutting depth predicted by the existing modified Burgers model, the range of the error ratio and the square sum of the residual error of the predicted rutting depth by the quadratic modified Burgers model are reduced by $70 \%$ and $60 \%$, respectively. It shows that this model can improve the accuracy and effectiveness.

\section{Data Availability}

Previously reported [THE PROPERTIES OF RAW MATERIALS] data used to support this study are available at 10.13705/j.issn.1671-6833.2016.04.015 and are cited at relevant places within the text as references. The [PERMANENT DEFORMATIONS OVER LOAD NUMBERS UNDER DIFFERENT TEMPERATURES AND LOADS] and [SIMULATED AND MEASURED RUTTING DEPTHS] data used to support the findings of this study are available from the corresponding author upon request and other data are included within the article.

\section{Conflicts of Interest}

The authors declare that they have no conflicts of interest.

\section{Acknowledgments}

This study was sponsored by the National Natural Science Foundation of China (51778038 and 52078025), Beijing Natural Science Foundation (KZ201910016017), the Program for Changjiang Scholars and Innovative Research Team in Universities (IRT-17R06), and China Highway Engineering Consulting Corporation (YFZX-2019-06).

\section{References}

[1] A. Alaa and A. A. Al-azzawi, "Evaluation of rutting depth in flexible pavements by using finite element analysis and local empirical model," American Journal of Engineering and Applied Sciences, vol. 5, no. 2, pp. 163-169, 2012.

[2] X. Ji, N. Zheng, S. Niu, S. Meng, and Q. Xu, "Development of a rutting prediction model for asphalt pavements with the use of an accelerated loading facility," Road Materials and Pavement Design, vol. 17, no. 1, pp. 17-27, 2016.

[3] S. Khan, M. N. Nagabhushana, D. Tiwari, and P. K. Jain, "Rutting in flexible pavement: an approach of evaluation with accelerate pavement," Procedia-social and Behavioral Sciences, vol. 104, no. 2, pp. 149-157, 2013.

[4] W. Li, "Experimental study on road performance of hot recycled asphalt mixture AC-20," Aging and Application of Synthetic Materials, vol. 48, no. 5, pp. 49-53, 2019.

[5] W. Lu, Viscoelastic Parameter Model and Low Temperature Evaluation index of Asphalt Mixture, Hefei University of technology, Hefei, China, 2015.

[6] W. Yang, D. Yang, and W. J. Xia, "Evaluation of high temperature flow deformation performance of asphalt stabilized 
macadam by creep test," Journal of Chongqing Jiaotong University (Natural Science Edition), vol. 27, no. 5, pp. 748-752, 2008.

[7] L. Huang, "Intermediate principal stress effect and failure criterion of asphalt mixture under triaxial compression," Journal of Central South University, vol. 47, no. 9, pp. 32253230, 2016.

[8] Z. Li, "Triaxial repeated load test on permanent deformation of asphalt mixture," Municipal technology, vol. 33, no. 4, pp. 156-159, 2015.

[9] J. Wang, "Simulation study on triaxial shear test of asphalt mixture based on discrete element method," Chinese and foreign highways, vol. 34, no. 04, pp. 256-261, 2014.

[10] M. W. Witczak, K. Kaloush, T. Pellinan, E. L. Basyouny, and Q. H. Von, NCHRP Report 465: Simple Performance Test for Superpave Mix Design, Transportation Research Board, National Research Council, Washington DC, 2002.

[11] A. A. Zokaei, T. Cesar, C. Cesar, and N. Soheil, "Impact of different approaches to modelling rigid pavement base layers on slab curling stresses," International Journal of Pavement Engineering, vol. 17, no. 10, pp. 861-869, 2016.

[12] G. Cerni, A. Corradini, E. Pasquini, and F. Cardone, "Resilient behavior of unbound granular materials through repeated load triaxial test: influence of the conditioning stress," Road Materials and Pavement Design, vol. 16, no. 1, pp. 70-88, 2015.

[13] P. Dae-Wook, "Traffic loadings considering temperature for pavement rutting life," KSCE Journal of Civil Engineering, vol. 10, no. 4, pp. 259-263, 2015.

[14] Zhang, "Study on high temperature performance of asphalt mixture based on repeated loading creep test," Journal of Wuhan University of Technology, vol. 36, no. 4, pp. 58-64, 2014.

[15] H. Zhang, "Triaxial repeated load test method for permanent deformation of asphalt mixture," Journal of Building Materials, vol. 11, no. 5, pp. 616-620, 2008.

[16] M. Liu, "Experimental study on the influence of gradation matching on the road performance of structural layer asphalt mixture," Highway, vol. 64, no. 5, pp. 219-225, 2019.

[17] R. A. Archilla and M. Samer, "Statistical model of pavement rutting in asphalt concrete mixes. Transportation research record," Journal of the Transportation Research Board, vol. 1764, pp. 70-77, 2001.

[18] R. Zhang, Study on Prediction Model and Flow Number of Permanent Deformations of Asphalt Mixture, Chang'an University, Xi'an, China, 2011.

[19] A. Loay, "Rutting prediction of flexible pavements using finite element modeling," Jordan Journal of Civil Engineering, vol. 5, no. 2, pp. 173-190, 2011.

[20] R. Zhang, Study on Rutting Prediction Model of Asphalt Mixture Based on Dynamic Modulus, Xi'an University of architecture and technology, Xi'an, China, 2014.

[21] P. Mackiewicz and S. Antnio, "Viscoelastic parameters of asphalt mixtures identified in static and dynamic tests," Materials, vol. 12, no. 13, 2019.

[22] S. Xu, "Prediction of asphalt pavement rutting based on viscoelastic theory," Journal of Tongji University, vol. 18, no. 3, pp. 299-305, 1990.

[23] R. Huang, Numerical Simulation of Permanent Deformation and Rutting Prediction of Asphalt Pavement, Southeast University, Nanjing, China, 2006.

[24] Z. Sheng, "Study on the aging properties of coal direct liquefaction asphalt-road modified asphalt," Clean coal technology, vol. 25, no. 4, pp. 33-39, 2019.

[25] W. Ji, "Performance evaluation of coal liquefaction residue modified asphalt and its mixture," Journal of Zhengzhou
University (Engineering Edition), vol. 37, no. 4, pp. 67-71, 2016.

[26] H. Wu, Study on the Compatibility of Coal Liquefaction Residue with Petroleum Asphalt, Beijing University of architecture, 2019.

[27] Jtg E. 20-2011, Test Code for Asphalt and Asphalt Mixture of Highway Engineering, Research Institute of highway science, Ministry of communications. People's Communications Press, 2011.

[28] M. Zhu, "Evaluating the rutting resistance of asphalt mixtures using a simplified triaxial repeated load test," Construction and Building Materials, vol. 116, pp. 72-78, 2016.

[29] S. Saride, K. R. Vijay, and V. Suraj, "Evaluation of rutting behavior of geocell reinforced sand subgrades under repeated loading," Indian Geotechnical Journal, vol. 45, no. 4, pp. 378-388, 2015.

[30] W. Zhou, "Performance of polyphosphate and rubber powder composite modified asphalt," Journal of Chang'an University (Natural Science Edition), vol. 38, no. 5, pp. 9-17, 2018.

[31] S. Li, "Analysis of the influence of old material content on the durability of warm mix recycled asphalt mixture," Journal of Chang'an University (Natural Science Edition), vol. 38, no. 5, pp. 31-37, 2018.

[32] V. Gao, Nonlinear Viscoelastic Creep Analysis of Asphalt Mixture, Xiangtan University, Xiangton, China, 2015.

[33] M. Ma, Viscoelasticity Research and Rutting Calculation of Asphalt Mixture, Changsha University of technology, Changsha, China, 2014.

[34] M. Wang, Characterization of Geometric Characteristic Parameters of fine Aggregate and its Influence on Performance of Asphalt Mixture, Harbin Institute of technology, Harbin, China, 2013.

[35] T. Gao, Construction of Optimal Models in Several Common Nonlinear Regression Analysis and Intelligent Realization of SAS, Academy of Military Medical Sciences, PLA, Beijing, China, 2012. 